\title{
Effects of incidental and intentional learning instructions on the free recall of naturalistic sounds
}

\author{
ROBERTA A. FERRARA, C. RICHARD PUFF, GERARD A. GIOIA, \\ and J. MELINDA RICHARDS \\ Franklin and Marshall College, Lancaster, Pennsylvania 17604
}

\begin{abstract}
An exploratory investigation of the effects of incidental and intentional learning instructions upon the free recall of a categorized list of naturalistic sounds was conducted. Subjects who performed a "physical" orienting task (judging whether a sound was louder in the left or right ear) recalled significantly less than subjects who performed a "semantic" task (judging the pleasantness or unpleasantness of the referents of the sounds) and subjects who were directly asked to learn the sounds. All groups showed significant categorical clustering, but there were no differences among the groups. These results further attest to the generality of Craik and Lockhart's (1972) levels of processing framework, and suggest that the retention of sounds varies with the degree of semantic involvement.
\end{abstract}

An increasing body of evidence suggests that the critical factor involved in the retention of a variety of stimuli is not the intent to learn per se, but rather the type of analysis done upon the materials. Consistent with Craik and Lockhart's (1972) levels-of-processing view, such studies indicate that orienting tasks which require consideration of the meaning of the stimuli lead to as much recall and organization as do intentional learning instructions, whereas orienting tasks which disregard meaning and focus instead on more physical properties of the items result in smaller amounts of recall and structure (e.g., Hyde, 1973; Hyde \& Jenkins, 1969). Such support for the importance of the kind of analysis has come mainly from studies involving the presentation of verbal stimuli. Craik and Lockhart argue, however, that "similar levels of processing exist in the perceptual analysis of sounds, sights, smells, and so on" (p. 675). Research involving pictures of faces lends some credence to this proposition (Bower, \& Karlin, 1974; Strnad \& Mueller, 1977). The present study further assessed the generality of the levels-ofprocessing framework by exploring the effects of different orienting tasks on the recall and organization of naturalistic sounds.

\section{METHOD}

\section{Materials and Apparatus}

The stimuli were 36 naturalistic sounds with an equal sampling from each of four categories. The categories and some representative instances were as follows: animal sounds (cows,

A report of the results of this study was presented at the Second Annual Undergraduate Research Conference, Georgetown University, March 1977. Requests for reprints should be sent to C. Richard Puff, Whitely Psychology Laboratories, Franklin and Marshall College, Lancaster, Pennsylvania 17604. rooster), household sounds (clock, telephone), human sounds (sneeze, laughter), and musical instruments (piano, trumpet). Most of the sounds were taken from soundeffects records and three were recorded by the experimenters. All sounds were correctly identified by at least $85 \%$ of the subjects in a pilot test. The mean duration of the sounds was $13.64 \mathrm{sec}$ with a standard deviation of 5.65, and they were separated by approximately 5-sec pauses. Three randomizations of the sounds were made, with restrictions that no sound immediately followed another from the same category and that no sound appeared more than once in the first five, or in the last eight, serial positions across randomizations. The sounds were presented via a stereo cassette recorder and stereo earphones.

\section{Procedure}

In the physical orienting task, the subjects judged whether each sound was louder in the right or left ear. The sound-level difference was detectable, but was not blatantly obvious. A single randomization was used to determine which ear received the louder sound. For the semantic orienting task, the subjects judged each sound as being pleasant or unpleasant in meaning. In doing so, they were instructed to consider what the sound represented and the thoughts they associated with it, rather than its physical properties. The subjects in the physical and semantic orienting task conditions were neither told to memorize the sounds, nor that they would later be asked to recall them. Judgments in both tasks were recorded on appropriate answer sheets. In the intentional learning condition, the subjects performed no orienting task and were directly told to memorize the sounds for a later test of retention. When the sound series ended, all subjects were asked to write as many of the names of the sounds (i.e., merely a noun, or a noun and a verb) as they could recall in any order in which they could remember them. They were given as much time as needed to write their responses on a lined sheet. Postexperimental questioning indicated that none of the incidental learning subjects had tried to memorize the sounds or had expected the recall test.

\section{Subjects}

The subjects were 36 students at Franklin and Marshall College, 34 of whom were enrolled in introductory psychology courses. Assignment to conditions occurred in a rotating sequence resulting in 12 subjects in each group, with equal numbers of males and females in each. 
Table 1

Mean Number of Sounds Recalled as a Function of Processing Condition and Blocks of Six Serial Positions

\begin{tabular}{lccccccc}
\hline \multirow{2}{*}{$\begin{array}{l}\text { Processing } \\
\text { Condition }\end{array}$} & \multicolumn{4}{c}{ Blocks of Six Serial Positions } & & $\begin{array}{c}\text { Mean } \\
\text { Total- } \\
\text { List }\end{array}$ \\
\cline { 2 - 7 } & 1 & 2 & 3 & 4 & 5 & 6 & Recall \\
\hline Physical & 2.42 & 2.42 & 2.25 & 2.25 & 2.58 & 3.33 & 15.24 \\
Semantic & 3.25 & 2.67 & 2.58 & 3.25 & 3.75 & 4.58 & 20.10 \\
Intentional & 4.58 & 3.67 & 3.17 & 3.08 & 3.50 & 4.33 & 22.32 \\
\hline
\end{tabular}

\section{RESULTS}

The mean number of sounds correctly recalled by the subjects in each group is presented in Table 1. It can be seen that the physical task resulted in poorer mean recall (15.24) than the semantic (20.10) and intentional (22.32) conditions. These data were analyzed according to a design including processing condition (physical vs. semantic vs. intentional) as a betweensubjects variable and serial position (six blocks of six sounds) as a within-subjects variable. The acceptable alpha level was set at .05 for this and all subsequent analyses. The results of the analysis showed a significant effect of processing conditions $[F(2,33)=5.70$, $\mathrm{MSe}=4.60]$ and of blocks of serial positions $[\mathrm{F}(5,165)=8.15, \mathrm{MSe}=1.16]$, but there was no significant interaction between processing conditions and blocks of serial positions $[\mathrm{F}(10,165)=1.58$, MSe $=$ 1.16]. Specific comparisons between the processing conditions indicated that the subjects in the semantic condition recalled significantly more sounds than those in the physical condition $[F(1,33)=5.13]$; subjects in the intentional condition also recalled significantly more sounds than those in the physical condition $[F(1,33)=$ 10.90], but there was no significant difference in numbers of sounds recalled by the subjects in the semantic and intentional processing conditions $[F(1,33)=$ 1.07 , with $\mathrm{MSe}=4.60$ in each case] .

Specific comparisons on the serial position data revealed that recall from the first block of six positions was significantly greater than from the middle four blocks $[\mathrm{F}(1,35)=5.52, \mathrm{MSe}=1.27]$, indicating a primacy effect. The finding of significantly greater recall from the final block than from the middle four blocks $[F(1,35)=56.81, \mathrm{MSe}=.68]$ indicates that there was also a strong recency effect. Recall from the final block of positions was significantly greater than from the initial block $[\mathrm{F}(1,35)=6.51, \mathrm{MSe}=1.23]$, suggesting that the recency effect was stronger than the primacy effect.

An examination of the extent of clustering in recall based on the four taxonomic categories of sounds was also conducted. The measure employed was the Adjusted Ratio of Clustering (Roenker, Thompson, \& Brown, 1971). This score expresses the difference between the observed and the expected number of category repe- titions relative to the maximum possible difference. Mean clustering scores of $.33, .50$, and .36 were found for the physical, semantic, and intentional processing conditions, respectively. Tests of the hypothesis that the mean taxonomic clustering scores were equal to zero yielded significant results in all three cases; for the physical condition, $t(11)=3.99$, for the semantic condition, $t(11)=9.04$, and for the intentional condition, $t(11)=4.23$. The amount of taxonomic clustering within each of the processing conditions was therefore significantly greater than the amount that would have been expected on the basis of chance. The analysis of the difference between the conditions revealed that they resulted in equivalent degrees of taxonomic clustering $[\mathrm{F}(2,33)=1.45, \mathrm{MSe}=.07]$.

In order to determine whether significant amounts of clustering occurred on the basis of the rating task dimensions in the two incidental conditions, adjusted ratio of clustering scores were based on categorization of sounds as those presented more loudly in the left or the right ear in the physical condition and categorization of sounds as pleasant or unpleasant in the semantic condition. The mean left/right clustering score in the physical processing condition (-.18) was not significantly different from zero $[t(11)=-1.32]$, while the mean pleasant/unpleasant clustering score in the semantic processing condition (.12) significantly exceeded the chance level $[t(11)=2.24]$.

\section{DISCUSSION}

The finding of greatest interest was that the intentional learners did not recall significantly more of the sounds than did those subjects who performed the semantic task, whereas those who did the physical task recalled significantly less than those in the other two conditions. These findings thus substantiate the generality of the levels-of-processing approach by showing that the same pattern of results obtains with naturalistic sounds as has been previously observed with verbal and pictorial materials. According to this view, the subjects who performed the semantic task processed the sounds to as deep a level as did those who were left to their own devices in learning the sounds and ex. pected the subsequent recall test. On the other hand, the sub. jects who did the physical task processed the stimuli to a more shallow level than did those in the other two groups, thereby producing a less durable memory trace and a smaller consequen 1 amount of recall.

The results of this study are also consistent with findings tha verbal interpretation is an important strategy for encoding naturalistic sounds (Bartlett, 1977; Bower \& Holyoak, 1973) The semantic and intentional processing conditions in the presen study probably entailed much more verbalization than was the case in the physical processing condition; thus, higher levels o recall were found in the former conditions than in the latter Such an explanation is compatible with the levels-of-processing framework, and is to some extent more amenable to empirica testing. However, it remains to be seen exactly why verbalizatio 1 should be such an effective encoding device for sounds.

Typical serial position effects were found for free recall o the sounds in all conditions. Primacy and recency effects wer obtained, with the latter exceeding the former. Furthermore serial positions did not interact with processing conditions. Th existence of primacy and recency effects for incidental learner 
is somewhat surprising since these subjects did not expect the recall test and should presumably have processed items in all serial positions to the same depth (the precise level depending upon the type of orienting task performed). It might be hypothesized that the items at the beginning and end of a list are more "perceptually distinctive" than the items in the middle which tend to become confused (e.g., Ebenholtz, 1966; Murdock, 1960). This idea also appears compatible with the depth-ofprocessing approach. Stimuli possessing greater perceptual distinctiveness might attract a greater amount of attention and, therefore, be processed more deeply or analyzed along more dimensions.

The analysis of the taxonomic clustering data did not reveal any differences between the processing conditions and thus did not parallel the results of the recall analyses. The levels-ofprocessing framework postulates that deeper levels of analysis make available existing cognitive structures, thereby activating greater numbers of common mediating associations which lead to more organization and recall. This proposition has been supported by previous incidental learning studies (e.g., Hyde, 1973; Hyde \& Jenkins, 1969) in which clustering and retention of associated word pairs was greater under conditions associated with deeper levels of processing than under those associated with more shallow levels. It is possible that the sound stimuli of the present investigation elicited the use of more alternative strategies, such as elaborative images, than is the case with verbal pairs. On the other hand, the sound categories may not have been as strong or salient as those represented by the word pairs used in previous studies, although this comparison cannot be carried out in the absence of comparable norms. However, the finding of significantly greater than chance taxonomic clustering in all conditions suggests that the categories were used to an appreciable degree for ordering recall of the sounds. Thus, the categories were strong enough to be detected, but still may have been too weak to mediate recall differences (e.g., Puff, Murphy, \& Ferrara, 1977). Perhaps organization is simply one of a number of processes associated with deeper levels of analysis. This interpretation is consistent with Craik and Tulving's (1975) view that optimal encoding or processing of words individually may be sufficient to support good recall.

The finding of significant amounts of clustering of pleasant and unpleasant sounds in the semantic condition may well have been due to a relationship between the pleasantness of a sound and the taxonomic category to which it belonged. For example, the musical sounds generally tended to be considered pleasant, whereas many of the human sounds (e.g., cough and scream) tended to be judged unpleasant. This factor in conjunction with the significant amounts of taxonomic clustering might have artifactually produced the pleasant/unpleasant clustering.

\section{REFERENCES}

Bartlett, J. C. Remembering environmental sounds: The role of verbalization at input. Memony \& Cognition. 1977. 5. 404-414.

Bower. G. H., \& Holyoak, K. Encoding and recognition memory for naturalistic sounds. Journal of Experimental Psychology, 1973, 101, 360-366.

Bower. G. H., \& Karlin, M. B. Depth of processing pictures of faces and recognition memory. Journal of Experimental Psychology. 1974. 103. 751-757.

Craik, F. I. M., \& Lockhart, R. S. Levels of processing: A framework for memory research. Journal of Verbal Learming and Verbal Behavior, 1972, 11. 671-684.

Craik, F. I. M.. \& Tulving, E. Depth of processing and the retention of words in episodic memory. Journal of Experimental Psychology: General, 1975, 104, 268-294.

Ebenholtz. S. M. The serial position effect of ordered stimulus dimensions in paired-associate learning. Journal of Experimental Psychology, 1966, 71, 132-137.

HYDE. T. S. The differential effects of effort and type of orienting task on the recall and organization of highly associated words. Journal of Experimental Psychology, 1973, 97. $111-113$.

HydE. T. S.. \& Jenkins, J. J. Differential effects of incidental tasks on the organization of recall of a list of highly associated words. Journal of Experimental Psychology, 1969, 82, 472-481.

Murdock, B. B., JR. The distinctiveness of stimuli. Psychological Review. 1960, 67. 16-31.

Puff, C. R.. Murphy, M. D.. \& Ferrara, R. A. Further evidence about the role of clustering in free recall. Journal of Experimental Psychology: Human Learning and Memory, 1977, 3. 742-753.

Roenker, D. L., Thompson, C. P., \& Brown, S. C. Comparison of measures for the estimation of clustering in free recall. Psychological Bulletin, 1971, 76, 45-48.

Strnad. B. N.. \& Mueller, J. H. Levels of processing in facial recognition memory. Bulletin of the Psychonomic Society, 1977, 9. 17-18.

(Received for publication February 2, 1978.) 